\title{
The Value of Economic Information in the Digital Society
}

José Poças Rascão, Polytechnic Institute of Setúbal, Portugal

iD https://orcid.org/0000-0003-2448-2713

\begin{abstract}
In the contemporary organizational context, the sharing and transfer of information and knowledge plays a significant role. The problem is that, in addition to being a new construct and still little studied, conceptual divergences are fed by the amplitude of the possible dimensions of analysis. In this context, the objective of this study arises in identifying the conceptualization of the construct of the value of economic information proposed in the scientific literature to support its better understanding and prospect of future investigations. A theoretical research was carried out through a systematic literature review followed by an analysis of the most relevant publications on the subject. The discussion of the relevant construct is considered in the context of contemporary organizations; however, it signals the importance of future studies of empirical and theoretical order to foster discussions on the subject today.
\end{abstract}

\section{KEYWORDS}

Communication, Economic Information, Information, Information Economy, Knowledge, Skills

\section{INTRODUCTION}

Much has been said about a new economy, in an environment of rapid transformations and new types of business. The main feature is the amount of information to be processed by organizations and people, which has grown a lot when compared to what was processed a few years ago. The Internet and the possibility of doing business in different ways have raised concerns about the processing of information necessary for decision making in the world of business and people.

Then, one asks: "Are new rules needed for the economy?" According to Shapiro and Varian (1999), the changes seen today are due to technological advances, but the laws of the economy continue to prevail. They haven't changed. The change in the economy is in the way in which information is used, hence the most appropriate term of information economics.

Second (Evans \& Wurster, 1984), the fundamental change in the information economy is not specifically some technology, but the new behavior of economic agents, which has emerged and is reaching a critical mass. The authors envision the emergence of connectivity between people. This movement has caused profound changes in the way organizations operate and the need to rethink the fundamentals of business strategy.

These transformations can be understood as the new forms of business, communication, and interaction. New technologies every day enable improvements that reduce obstacles such as time 
and space. Both people and organizations have exchanged more information, whether by sending messages or exchanging files. The emergence of connectivity creates several benefits never imagined. A few years ago, people exchanged music through cassette tapes, vinyl records and CDs. Until then the exchange (or sometimes loans) of music was conditioned to an exchange of physical goods. Who could have predicted that one day people would be exchanging music with each other digitally, online, without any physical contact? Napster understood what connectivity would be and provided people with something new.

Second (Evans \& Wurster, 2000), connectivity would be an opportunity created by technology. Technology in turn would be the instrument that created such an environment. It is now necessary to understand the fluid that irrigates this environment, making technology work and connectivity exist - information.

This article is part of the literature review of the ongoing doctoral thesis project, which has as main objective to develop and test a conceptual model of measuring the use of information by the top management of organizations. To date, potential dimensions of analysis have been identified. These dimensions will become the constructs to be tested, seeking, through confirmatory factor analysis, in the next phase of the research, their confirmations and the structuring of the scale for measurement.

\section{METHOD}

\subsection{Theme and Search Problem}

The value of Economic Information is a little-known term in the world of business and people. Knowledge is something that resides in the human mind, built on the individual's relationship with the world. To understand the information, it is necessary to identify the environment in which this process occurs, that is, the organizational environment. Organizations are formed by groups of people with different objectives who unite in favor of one or more objectives, usually delimited by the vision of managers.

Organizations are complex systems with the predominance of information when, the whole is more than the sum of the parts. And the more complex, the more its whole far outweighs the parts and the more it becomes autonomous and unpredictable, because it escapes more and more mechanical determinisms. The growing importance of emerging, independent properties that make up the complex system implies the preponderance of information (of "form") on matter (the "substance"): all complexity is also a dematerialization. Complexity and density of information are synonymous (Halévy, 2008, p. 11). Second (Mattelart, 2002), information is in the whole context of society and organizations.

Managers are people who take up much of their time making decisions of various natures and dimensions. The requirements for the time available for decision making appear to be higher than the total time available. Decisions of great importance are mixed with trivial decisions. This diversity of decisions tends to increase with the level of responsibility and becomes particularly pronounced in the case of managers of higher hierarchical level. The role of managers involves an overly broad set of activities, analyses, decisions (including strategic ones), communication, leadership, motivation, evaluation, and control.

Decisions and actions are the final product of the work of blinds and people. The strategic decisions taken explicitly or implicitly precede any action, regardless of the process, by which they are taken, either by the formal hierarchy or by the broad participation of the intermediate level g-blinds or by omission. The decision-making process is complex, so it poses some problems to the-blinds, in terms of approach methodology, to choose relevant and timely information for decision-making, among the various alternatives. 


\subsection{Questions for Debate}

1. What do companies use to compete in the market?

2. Is there an information economy in the Digital Society?

3. How to measure the Valor of Economic Information in the Digital Society?

\section{GOALS}

The Information Sciences have evolved into new stages of dialogue and insertion in the Social Sciences. Reflection on the evolution of information sciences, its relations with other sciences and as a model of science as a whole, is fundamental for research to continue and incorporate all accumulated knowledge. Since scientific research is one of the main ways for the formulation of theories of an area, what is perceived is that the research of information sciences has been over the last decades, consolidating itself and opening new horizons of discussions. Great contribution has been made by professors and researchers at the various International Universities.

Some important steps have been taken to theoretically strengthen the area of Information Sciences and that research is expanding and has a Scientific Community that over the years has been consolidating internationally. There are many different challenges for information sciences today. As applied science, it needs to respond to the search for information in the Digital Society and, as an object of research, to the fundamental conceptual needs of the area. The realization and sociability of research are the safest ways to create and share new paradigms. Thus, it becomes increasingly important to seek the theoretical, philosophical, and social foundation in the Field of Information Sciences and above all to further strengthen its scientific community.

This article seeks to contribute to the understanding of the conceptual importance of the term the Value of Economic Information, in the Digital Society, in the context of Business Sciences and Information Sciences, from a theoretical framework.

\section{METHODOLOGY}

As for its nature, the research is qualitative since it does not claim to quantify events or privilege the statistical study. Its focus is on obtaining descriptive data, i.e., the incidence of topics of interest in two fields, the Information Sciences and The Economic Sciences. Regarding the extremities, the research is exploratory in nature and descriptive in nature, to the extent that the technique used is categorized, consensually, as a study of direct documentation, which provides for consultation with sources related to the study in different media, printed or electronic.

The complexity and turbulence of the digital society have led to the globalization of information as essential processes for the development and innovation of science and technology. Information is the source of the energy that drives the Digital Society's engines, but to use it we need to convert it into a usable form: knowledge.

The digital society is a complex society of technological innovation and communication, in which there is the creation of new environments and changes in people's dynamics, in the way people understand reality, changing the way, how they relate to the environment, to other people and how they conceive themselves in the face of their own reality. Both senses can be understood, because of the informational revolution, promoted mainly from the attempts to understand human intelligence, via computational bases.

Therefore, the premodern notion of information as in-formation that forms or shapes the human mind is gradually replacing information as a "data structure" (Boland, 1987) representing intangible realities too great to be experienced directly by people's sense. Information has become an objective object, separate from human experiences and minds. 
The research method is likely to cause two or more sciences to interact with each other. This interaction can go from simple communication of ideas to the mutual integration of concepts, epistemology, terminology, methodology, procedures, data, and research organization.

This is an exploratory study that seeks to clarify and organize the concepts presented in the literature of Information Sciences, Economic Sciences and Business Sciences. It is not a proposal of new terms and concepts, but an organization that allows identifying a common denominator, among the different concepts already indicated in the literature, so that it allows its grouping by identity, application / use, and pertinence / aggregation of value in the context, in which the terms are inserted. Data collection is characterized by bibliographical research, terms, and concepts.

It is necessary to understand, through a theoretical review of the concepts, through the historical reference documents; of a psychosocial analysis of the concepts of information, knowledge, communication, information economy applied to the information sciences, the economic sciences and the business sciences; the normative framework in which they fall; the Internet as a platform for the exercise of human action and the problems associated with it; digital data, citizen surveillance; social engineering of Power; online social networks and spaces of trust and conflict.

It is a descriptive and analytical approach seeking to know and analyze existing cultural and/ or scientific contributions on these aspects, from the review of existing literature. The research was structured based on the systemic approach, for the understanding of the problems of Information, Knowledge, communication, of learning and the Information Economy, in this Complex and Turbulent Society. We represent this conceptual network, as follows in Figure 1:

It presents the model of approach for intervention in information actions, in the academic space, with the purpose of production and information sharing and knowledge, among the participants, and promote the development of skills of search, recovery, organization, appropriation, production and dissemination of information relevant to scientific researchers, managers and other interest groups, in society.

\section{RESULTS}

\subsection{Theoretical-Methodological Framework for Research}

\subsubsection{Evolution of Information Concepts}

\subsubsection{Concept of Perception versus Information}

The perception of information not only influences our view of information, but also our perception of the information system (Klein \& Hirschleim, 1987), our perception of communication (Mokros, 1993; Schement, 1993) and the conduct of research (Newman, 2001; Schement, 1993). This means that the perception of information, which we prefer to call information concepts, has a profound influence on the field of information science.

The concept of information fascinates many scientists from different fields, such as biology, psychology, computer science, sociology, economics, management, political science, statistics, philosophy, communication and information studies (Mokros, 1993; Newman, 2001; Ruben, 1993; Schement, 1993). In all these areas, information is an important concept, but at the same time none of them can claim that information is relevant only to them.

Information should be an interdisciplinary concept. This means that information concepts must be studied in different disciplines. It also means that the concepts of information are not only relevant in the field of information science.

The concept of interdisciplinary information did not arise, and no unifying theory is presented as imminent (Schement, 1993). When information is defined "abundance and diversity confuse us" (Braman,1989, p. 233). A tantalizing conclusion we have reached is that the meaning of information 


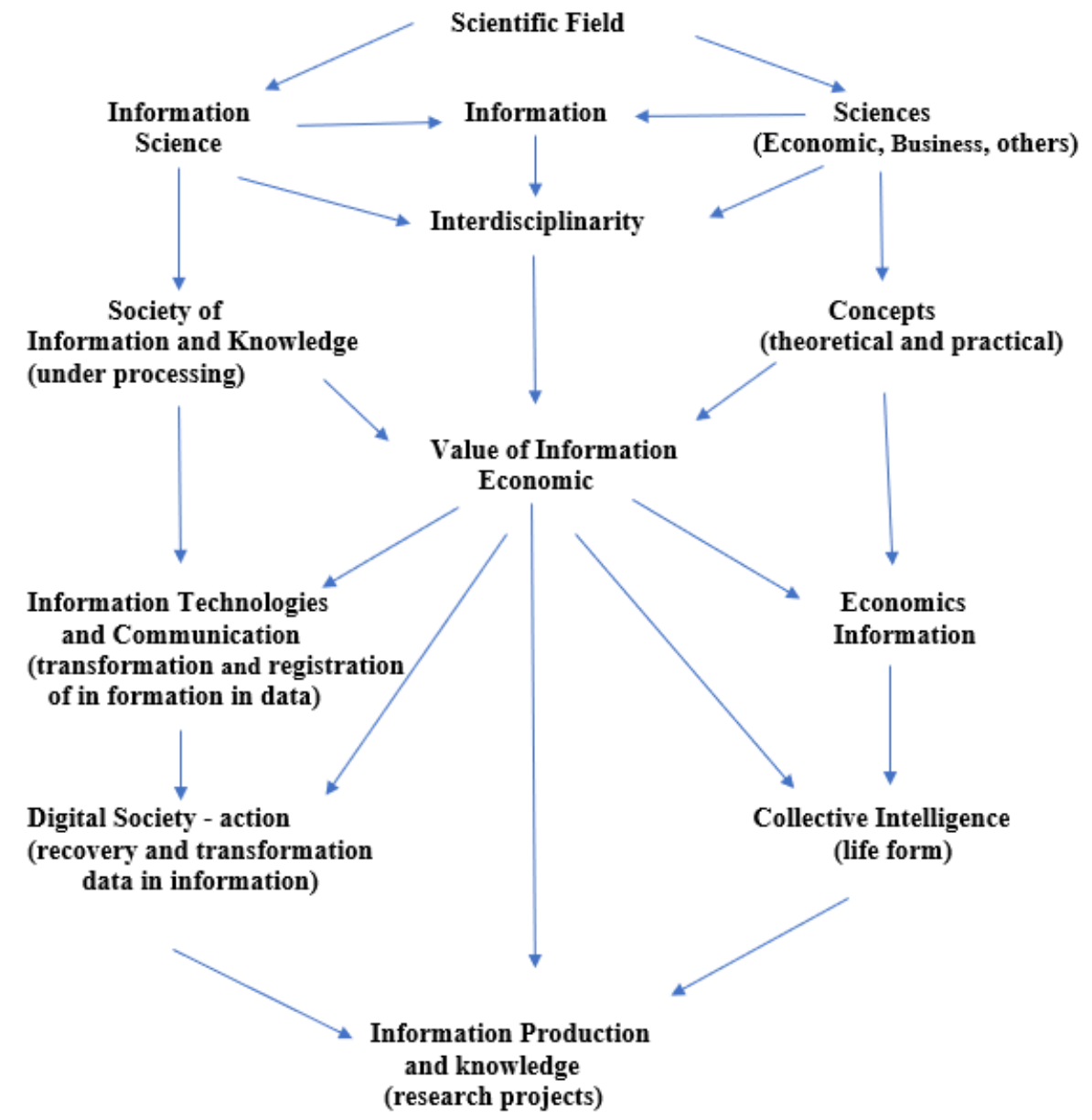

depends on the context. While many argue that we need a theoretical perspective of information (Devlin, 1999; Aefiner, 1999; Newman, 2001).

We do not intend to define a theoretical perspective, but only to present the different concepts in different disciplines, as well as a critical analysis of the different concepts. (Newman, 2001) describes a variety of concepts in different sciences that can be grouped as follows:

- Probabilistic concept.

- Concept of information processing.

- Ecological concept of information.

- Social and organizational concept of information.

The probabilistic concept of information is that low probability events represent a high content of information. An important application of this concept is information theory (Shannon \& Weaver, 1949, in Newman, 2001). In this theory, the mathematical representation of the transmission of a message is presented, as if the information were a measure of predictability. Lógica, cybernetics and philosophy also correlate information with probability (Fisher, 1934; Carnap \& Bar-Hillel, 1952; 
Popper, 1965; Mackay, 1969, in Newman, 2001). But these concepts differ in important ways, such as in the interpretation of probability and in the semantics of information. About the semantics of information, many concepts see information as a reduction in uncertainty.

The concept of information processing (or cognitive concept) focuses on the thinking of cognitive psychology. However, this concept, thought and information processing are analogous. Information is the product of thought and this increases knowledge about anything. The model of the cognitive process and the internal representation are the first concern of this approach.

The concept of ecological information is not created, but is present in the world, of the environment, in each situation. Organizations actively collect this information from the outside world. An important extension of the ecological approach is the theory of the situation. This is reconstructed on a mathematical basis and makes a clear distinction between information (content or information) and its representation.

The social and organizational concept of information is part of the sphere of work: work associated with the concept of information economy. In this category, the information concerns the processing of the same and the information pyramid model is often used. In this model, it is necessary to analyze a data to produce information and the information must be processed to produce knowledge. An important ingredient of information economics is the quantification of "work information" and "information product", used, among other things, to show the importance of knowledge in modern economies (Wallerstein, 2000; Myrtle, 2001; Brandt, 1995; Nicholas, 2000; Handy, 1990;Hauknes, 1999).

In the well-known effort (Porat, 1997, in Newman, 2001), information is associated with reduced uncertainty. The research of the information science focuses on the process of information in the Organization and the need for information from decision-making support managers. The satisfaction of this requirement may result in a reduction in uncertainty, which contributes to better decisionmaking (Schement, 1993).

\subsubsection{Philosophical Concept of Information}

Belkin (1978) contributed many studies to an important problem of science of information: the question of the definition of an appropriate concept of information forth Science of information. Although Belkin discusses the concepts of information used only in the science of information, many of these concepts originated from other fields and/or are used in a wide variety of these (Belkin, 1978, p. 82):

- Information as Fundamental Category: Information is seen as something essential to the existence of the universe as a basis, but a different category of matter.

- Information as Property of Matter and Consciousness: Information is not considered, as a special category, but as property of matter (i.e., objective information) and or property of consciousness or reflection of an individual (i.e., subjective information).

- Information as social-scientific information is based on the classification of Mikhailov, Chernyi, and Giliarevskii (1975, in Belkin, 1978). This classification divides the intuitive idea of social and non-social information, social semantic information, and not semantic and scientific and non-scientific and non-scientific information. According to Mikhailov, Chernyi, and Giliarevskii (1975), information is limited by the science socials;

- Information as Event: Information is seen as the expression of the mental image that occurs when we receive a message.

- Information Table: The information is not seen as an event, but as the resulting structure and event. For example, information is the resulting structure in the mind of a sensory data or some experience.

- The information as probability of occurrence of an event comes from the theory of information of Shannon and Weaver (1949); 
- Information as Message: Vague concept in which information is confused with the content of a communication.

\subsubsection{Concept of Information in the Context of Decision-Making}

Cleveland (1982) characterizes the information as follows:

- Information is "human" - there is only information through human observation.

- The information is multipliable - the more we use it, the more useful it becomes; the basic limit is the biological age of people and groups.

- The information is replaceable - it can replace other resources like money, people, raw material etc. For example, the accumulation of information in the automation area replaces several million workers annually.

- Information is transferable - the speed and ease with which information is transferred is a considerable factor for the development of all areas of knowledge.

- Information is diffuse - it tends to become public, even if our efforts are the other way around.

- The information is shareable - goods can be exchanged, but in the exchange of information, the seller continues to own what he sold.

Braman (1989) suggests a hierarchy of information definitions that are used in the context of decision making. The hierarchy is based on three dimensions: the level of opportunity, the level of complexity and associated with power (which is guaranteed for information, streams, and usage). These dimensions group the definitions of information into four groups:

- Information as a resource.

- Information as something useful.

- Information as a standard perception.

- Information as an essential feature of society.

Information as a resource is associated with a lower level of opportunity, complexity, and power, while information as an essential characteristic of society is associated with the highest level in these three dimensions.

- Information as a resource treats information as an isolated and distinct entity without energy. Information is divided into the parts that make up the body of knowledge or flows of information in which it can be organized (Braman, 1989, p. 236).

- Information as something useful focuses on the process of exchanging information between people. This concept requires chain production, through which information gains economic value (Porter, 1980). The chain includes steps such as creation, processing, and distribution. This implies greater complexity of the social structure "including suppliers, customers and the Organization to maintain the market" (Braman, 1989, p. 238).

- Information as a standard perception requires information and context. Information "has a past and a future, it is affected by the stimulation of casual factors and the environment" (Braman, 1989, p. 238). Compared to information as useful, the scope of the phenomenon covered by this concept is extended. Information can be used to articulate social structures. This definition sees information as an element of reducing uncertainty.

- Information as an essential characteristic of the information-oriented society as "an active function constructed in context" (Braman, 1989, p. 239). Information becomes an actress that affects the environment and creates a social structure. 
This definition treats information as an essential feature of society. It applies to all phenomena and processes in which information is involved and can be applied to the social structure with some degree of articulation and complexity (Braman, 1989, p. 241).

\subsubsection{Concept of Information Process, Such as Knowledge and How to Do Thing}

Buckland (1991) identifies three "primary uses" the term information:

- Information as process.

- Information as knowledge.

- Information as such.

The information process refers to the act of informing / being informed. When it is reported, what you know is changing.

"Information as knowledge" refers to what is seen as process information. It is the knowledge that is communicated. Buckland (1991) sees information, as a reduction of uncertainty, as a special case of "information as knowledge". Some information increases uncertainty.

Information as something that refers to things that are informative, things become informed. Buckland also examines different things (data, text, subject material, events) and concludes that everything is or should be informative. It argues that the virtue of being information as a thing is situational and depends on subjective judgments. Buckland (1991) summarizes the main concepts of information tree, in terms of two distinctions:

- Between entities and processes.

- Among intangible and tangible asst.

Buckland (1991) distinguishes four aspects of information, but only three about the use of information. The fourth aspect of information is information processing. This refers to the execution, manipulation and deduction of new forms or versions of information, as a thing.

\subsubsection{Interdisciplinary Information Concept}

Ruben $(1992,1993)$ has different proposals to "provide an interdict communication informationcommunication relationship" (Ruben, 1992, p. 22).

Ruben does not justify this classification and does not refer to any example of these concepts in the literature. However, it sees information as an interdisciplinary concept focused on the relationship between information and communication. Here it explicitly describes a wide variety of fields, such as biology, economics and cyber, mathematics, sociology, and communication studies:

- Information has a potential meaning for a living system, but this potential is not yet up to date.

- The information is the information that has been transformed and configured for use by an individual.

- Information includes the sharing of information/knowledge base of society and other social systems.

\subsubsection{Concept of Information in Communication}

Schement (1993) reviews 22 definitions of information from different areas, such as economic science, physics, information, and communication. Although its focus is on the study of information and communication, it analyzes its interdisciplinary aspects, because the definitions of the different fields are compared. 
Based on these definitions, it distinguishes "fundamental terms whose outline of current of thought is the nature of information" (Schement, 1993, p. 7). Information as something treats information as a thought, being a (non-material) thing. According to Schement this concept is the most used of the three concepts. Two examples of this concept are:

- Information is an entity; something that has no mass or energy" (Diener, 1989, in Schement, 1993).

- Information is a consistent collection of organized data or messages that have meaning or can be used by the human system (Ruben, 1988, in Schement, 1993).

\subsubsection{Concept of Information as a Process}

This concept of information process sees information as the phenomenon for informing or changing a particular situation. An important subtheme of this concept is the vision of information such as the reduction of uncertainty, a common view among economists, managers, and computer scientists. The last concept, information as a product of manipulation is seen as a thought is something that must be manipulated to exist. Example:

The information is produced because of a process on the data (Hayes, 1969, in Schement, 1993).

According to Schement, these information perceptions are related to different perceptions of communication. He argues that these two concepts are inextricably linked to each other.

\subsubsection{Real-World Information Concept}

According to Gelepithis (1999) information is the central concept for the information sciences community. A considerable number of disciplines related to information have been involved in the development of other closed concepts related to information (e.g., sign, symbol and meaning (Shannon \& Weaver, 1949 in Newman, 2001).

Gelepithis (1999) is concerned with the clarification of these concepts and their consequences in the fields of information science. However, his proposal is not present in the table of contents of the various concepts of information in different disciplines. Gelepithis (1999) presents seven concepts of information:

- Information in terms of the probability of a signal.

- Information as a state.

- Information in terms of knowledge and meaning of the mental level and as a mental and nonmaterial entity.

- The information in terms of signal concept as primitive.

- Information designed in terms of the world tree.

- Information in terms of true condition.

- Information as a basic property of the universe.

The problem with these concepts is that they are very brief. Information in terms of sign as primitive is referred to by Stamper (1985) in that it proposes semiotics (signal theory), as an appropriation of information theory (Shannon \& Weaver, 1949). He argues that the idea of a sign is "the very primitive on which information science is based" (Gelepithis,1999, p. 195).

Signals can be described as physical objects, events, or properties of objects and events that are available to represent a function in human behavior. The information is a measure of some ownership of a signal. The measurements differ from each other (e.g., entropy measurement and subjective measurement) and, in addition, information has different meanings. 
The information designed in terms of Popperian tree design is the basis of Popper and Eccles (1977). They argue that we only accept things as real if they can interact with material things. Distinguishes three realities or three worlds:

- World 1: The world of physical objects and states.

- World 2: The world of states of consciousness (e.g., subjective knowledge, creative imagination experience);

- World 3: The world of knowledge for purpose (e.g., products of the human mind, theoretical systems, scientific problems).

According to Popper, these worlds interact with each other. However, it is still unclear what (Gelepithis, 1999) is bad through the information conceived in terms of these three worlds.

\subsection{The Globalization of Information}

In an age of globe-wide communications, information is the link that unites us. By being able to transmit it in large quantities quickly from continent to continent, we have transformed a largely separate and diverse world into a single global megaloon. The messenger on foot gave way to information highways and social networks worldwide. Anything may be an asset to be compiled, stored, duplicated, sold, stolen and sometimes a source of murder. Many people around the world spend their working days gathering, studying, and processing information. Industries have been developed to produce equipment and software to store and process information.

Organizations have many physical assets that must be managed, such as products, financial goods, and others. Information about the environment in terms of strategic management today requires permanent attention and can be considered as the most asset, so in so-called knowledge-based economies, information is taking on an increasing share of the cost of doing business successfully.

Although we can store it using various physical supports, the information itself is not physical, but abstract and so little purely mental. Knowledge is stored in people's memories, but information is out there in the world. Whatever it is exists somewhere between the physical world around people and the mental of human thought.

In industrial society, crude oil was an important source of energy used to move engines and feed factories. But before the chemical energy of oil could be unleashed, crude had to be refined, that is, in usable forms such as gasoline and heating fuel. Similarly, information is the source of energy that drives the "engines" of the so-called knowledge society, but to use it we need to convert it into a usable form: knowledge.

But when we refine the information to turn it into knowledge, quality weighs more than quantity. When we convert information into knowledge we add value to it and make it more expensive. Over the past few years, in most Western countries it has been seen that the industrial sector, largely responsible for the wealth they have accumulated since the 19th century, is losing weight in gross domestic product (GDP) compared to the services sector, resulting from the transformation of industrial society into information society for three reasons:

- Organizations increasingly rely on the intelligent use of information and are transforming into information-intensive organizations.

- People in their daily acts consume large amounts of information both in terms of leisure and in terms of business.

- The covert information industry has emerged within the diversity of the service sector as an entity sufficient to be a sector (perhaps the best) of the major sectors of the economy (primary, secondary, and tertiary sector). The industry can consist of three sectors: information content, 
information distribution (access centres and distribution channels, such as telecommunications operators and the Internet) and information processing (information technologies)

The transformation of organizations into informational intensive is perhaps the clearest detonator of the change to information society. The analysis of the most successful organizations in the world seems to indicate that this originated in the best management of information and knowledge about the global and immediate environment, that is, those that have better identified the needs of the market and that have better adapted in terms of configuration, methods, processes and cultural forms that allowed combining the external information with that generated internally to generate distinctive competitive advantages (Porter, 1998).

Globalization, a concept often used for business organisations, must be seen beyond the opening or not of borders, countries, markets and organisations themselves. The information, regardless of its geographical origin or the time frame is at our fingertips via the phone keyboard, computer, or television screen. The world is increasingly seen as a field of opportunities, business, and markets, since with the evolution of information systems, supported by information and communication technologies, are revolutionizing management concepts, the attitude of managers, the actions of organizations and, above all, the positioning of markets. It is necessary to reconsider concepts such as Strategy or Organization or structure, emerging new concepts such as Organizational Urbanism, for example.

\subsection{The Economic Reality}

Economic theory has difficulty explaining the main economic events of recent years and could not have foreseen them. All predictions have been surpassed by reality. The economic model that the world needs is a model that will have to conceive the economy as also as "ecology", "environment" and "configuration", as being composed of tangible and intangible variables (Drucker, 1989).

Economic policy requires politicians to understand the key concepts of economic theory since the economic reality is too complex. What we have been witnessing is an "economic policy" aimed at specific problems, that is, what we can call "economic hygiene" or "preventive economy" whose objective should not only be to "cure" a crisis, but to strengthen the health of the economy to make it resistant even to severe attacks of crises.

Contemporary economic theories assume that the only economy that matters is the economy of each country. They recognize that many economic transactions cross national borders. However, they imagine that these transactions can be controlled through the management of each country's internal economy. This axiomatic assumption does not match reality. Economically active people and businesses have never submitted to macroeconomics and have always managed to "sabotage" their yoke. In addition, there are things that happen in the microeconomy that profoundly affect the macroeconomics, but that are not controlled and are virtually unaffected, with what happens with currency, credit, interest rates and taxes. Today there is the world economy.

Keynes assumed that the speed of movement of money indicates the pace at which people spend their money and that it remains unchanged to this day. The facts clearly indicate that people can change their habits of speed of movement of money quickly, unexpectedly, and quite independent of the current economic policy (Shumpeter, 1934).

In fact, it is the ability of people and businesses to change the speed of movement of money that makes all government attempts to control the economy to be unsuccessful. For example, if people decide not to invest their cash, the economy does not grow, but if people invest their cash, the economy grows. This shows that a legitimate decision profoundly affects and largely determines the national macroeconomics. However, the economist has nothing to say about, how to make this decision, nor has the means to include it in his models.

Contemporary economic theories have great difficulty in dealing with the impacts of technological development, innovation, and social change. Economists know the importance of technology, innovation and social change and have already made several attempts to incorporate technology 
and changes into their models, but all attempts have failed and for the same reason: there is little correlation between monetary policy, credit, and interest rates, undertaken and innovation. However, undertaken and innovation can change the economy in a short period of time, thus showing that they are true masters - not macroeconomics.

The world economy is now a distinct reality from national economies, which it deeply affects and in extreme circumstances, it controls. The world economy sets strict limits on macroeconomics, especially about currency, credit, and interest rates. Economic rationality does not mean the same thing in the world economy, where time intervals of economic decisions are also different. These intervals are short, such as, the decisions regarding the exchange rate and the market of products and services, business decisions - distinct from commercial decisions - however, the time intervals in the world economy are longer.

In the world market, "sales" are not sales: they are returns on long-term investments. What matters is the total return over the entire life of the investment. This is of course also "maximizing profits"; but that's not what microeconomic theory means by the term. It is not just the reality that runs counter to the economic model with which we currently must work. There is a new challenge to the theoretical foundations and methodology of economics - a subtle, insidious, and potentially as serious challenge as reality.

\subsection{Information and Knowledge}

In neoclassical economics, information and knowledge are free goods or as any other tangible product. The perfect market model was built for industrial society with the preliminary intention of theorizing the transaction of tangible, physical products. There was no need to model information and knowledge, as objects of exchange, simply because the products of information, as we understand them today, hardly existed.

Instead, economists saw information and knowledge as merely meaning to support the exchange of physical goods. Being "only support of exchange", information and knowledge could be assumed, as free goods, which are miraculous data and are resources without constraints and not problematic, so they can be excluded from economic analysis. Treating information and knowledge alternatively, as all other physical products serve the same purpose.

By denying information and knowledge a distinctive character and its role in economic processes, the price could be assumed to contain all the information that economic operators would need to know to carry out transactions efficiently. Thus, information and knowledge could be rejected without the perfect market model being lost some of its exploratory power.

These two neoclassical views of information and knowledge lead to a paradoxical situation for information management - influenced by neoclassical economics, its identity is based on a well-established theory that denies its economic contribution or sees information management as a "normal" business requiring no special attention. When information and knowledge are perceived as free goods, the verdict is that information management cannot add any economic value. Free goods are economically insignificant. And when information and knowledge are considered equal to other physical products, organizations can do information management without a specialized function.

In both cases, the economic value of information, ICT and information management are difficult to substantiate and verify, which may explain why many organisations use outsourcing. Moreover, the vision of information, as a free product, may not be easily set aside, as irrelevant to information management. The experience of organizations with the current Internet for example, information researchers were not prepared to pay for information or information services. Information as a free product explains the sometimes-frantic research of alternative business models.

These economic judgments of information management can be contradicted by questioning their underlying assumptions. If all the information needed for decision-making were included in the price, no one would be willing to invest in the collection, production, and communication of the information. A simple real-world observation, however, is that people, organizations, and society 
spend a lot of time, energy, and money on informational activities. In addition, except for industrial society, many digital information products exist and are sold on the market. Finally, information and knowledge are increasingly seen as the main sources of wealth creation in individual, organizational and society competition. Consequently, economists have created two images of information and knowledge that best resemble the real world: information and knowledge, as idiosyncratic products and as idiosyncratic or active resources.

Both views of information and knowledge involve the intellectual focus of the inherent and idiosyncratic properties of information and knowledge that make them behave differently in economic terms. Those inherent properties and their implications in practice could provide a wholesome basis for information management identity.

However, these relatively new views of information and knowledge in information management also present with idiosyncratic problems. Regarding the view of information as an idiosyncratic product, economists call it "the information economy" (Shapiro \& Varian, 1999) because it has not yet been possible to quantify the informative content of these products. Instead, pricing such products is based on technology for storing, distributing, and transporting objects of information. A more appropriate name for this branch of the economy would therefore be the economics of information technologies. Nevertheless, the information economy deserves to be included in the information management curriculum. It is a part of the digital world that is not contemplated by other academic disciplines.

In the last economic vision, information and knowledge are idiosyncratic resources or resources capable of generating wealth on their own. Reconstructing, among others, the vision of the knowledgebased company (Boisot, 1998), the practical implication of economic differences with physical resources is so profound that knowledge-intensive organizations need a new theoretical perspective.

This statement is confirmed by Maes (2007) which indicates that the core of information management is moving from information systems and information and communication technologies to information management, as a resource of business. With information and knowledge, as the heart of the business, the added potential value of information management would become immediately clarified. Nevertheless, the vision of information and knowledge as a resource is not without its own intellectual challenges. By calling information and knowledge a resource or a resource that symbolically transforms these entities into objects, which influences our understanding of what information and knowledge is and what we can do with them.

Due to the limited space, it cannot refer to other recent developments in the economy, such as defining information as the reduction of uncertainty, but that does not change the bottom line: the economic reasoning always imbued with the logic of objectification. As a result of this orientation to objectivity, three fundamental problems arise that relate to objectivism in general and thus to all four economic views of information and knowledge.

\subsection{Information in Organizations}

Organizations (public and private) will have fewer and fewer levels in their organisational structure in the future, as they will be based on highly skilled resources (knowledge workers) that manage and discipline their own performance through organised feedback from their colleagues, customers, and suppliers, i.e., they will be information-based organizations.

Demography itself requires this change. Among employees, the center of gravity is rapidly moving from manual and office workers to telework knowledge workers who reject the commandand-control model that companies copied from the military many years ago. The economic context also determines this change especially regarding the needs of companies to innovate and assume the role of entrepreneurs. But above all it is information and communication technologies that require and facilitate this change.

An organization can exist without information and communication technologies to process its data, i.e., they can use pencil and paper technology. But as information and communication technologies 
become relevant, organizations now have to engage in analysis and diagnosis, i.e., information. As soon as managers start to use more information and less data, their decision-making processes will significantly improve, i.e., they will manage the information and not the data stored on computers.

For example, in the analysis of a capital investment we need at least six items of information: the expected rate of return, what will be paid during the expected productive life of the investment, the current value and all returns during the expected life of the investment, the risk of not making the investment or deferred, the cost and risk in case of failure and the opportunity cost (which are the return on other investments alternative). These calculations with pencil and paper technology would take several years, today anyone with a computer spreadsheet should be able to perform the calculations in a short time.

With this availability of information, the analysis of a capital investment is no longer an "opinion" and becomes a "diagnostic" information, that is, a rational weighting of alternatives. With this availability of information, the capital investment decision is no longer an opportunistic financial decision determined by number to become a business decision based on the probability of several alternative strategic assumptions. As a result, the decision at the same time presupposes a business strategy and challenges that strategy and its assumptions. What was once a budgetary analysis exercise becoming an analysis of key guidelines.

When an organization concentrates its ability to process data on information production, the second major impact is on its organizational structure, that is, the number of administrators and administrative staff begins to be significantly reduced and relocated. Another big change will be when managers start to wonder what information they need to run the business, what sources and how they flow. When they answer these questions, they will state that there are many bodies in the structure because they had never questioned themselves for this and had never answered these questions.

Organizations still have data in abundance but have always used that data for control and not to produce information for decision-making support. Information is data endowed with relevance and meaning. To convert data into information you need knowledge, and this by definition is specialized (in reality truly knowledgeable people tend to overspecialize, because there is always much more to know). Organizations increasingly need information managers than the traditional command-andcontrol structure.

In information-based organizations knowledge does not exist only in management (top management), but also in intermediate managers and operational managers who manage business units or areas of responsibility (e.g., financial, personal, marketing, etc.) and manage the day-to-day (operational managers), that is, they guarantee the daily operation. The tendency is to infuse knowledge from top to bottom and not from bottom to top.

As a result, a good part of the work will be done differently. The work itself will be carried out mainly by teams formed for the execution of certain tasks (projects). The traditional researchdevelopment-production-marketing sequence is being replaced by the synchrony where the specialists of each function work as a team (interdisciplinary) from the beginning of the research to the consolidation of the product, in the market. One thing, however, is clear: an information-based organization requires self-discipline and individuals take responsibility for their relationships and communication.

An information-based organization needs to have clear, simple and common objectives that can be converted into specific actions and that while focusing on a single objective or at most a few objectives, i.e. the organization must have a clear strategy and the objectives should be detailed for each business unit or area of responsibility and operational, but whose performance expectations contribute in a coherent way to achieving global objectives.

Therefore, the organizational structure must be defined according to feedback that compares the results and expectations so that each of its employees can exercise self-control. Itis also necessary for everyone to take responsibility for the information they need for decision-making support. 
The responsibility for information in front of others is increasingly well understood, especially in medium-sized organizations, but the responsibility for information in front of itself is still being relegated. All employees of an information-based organization need to know what information is needed to make decisions and make their contribution to the results (operational, intermediate, and top).

This is perhaps the most radical break with the way, as so far the most computerised organisations are still being managed. Even in the most computerized organizations, people either assume that the more data they get the more information they will have (which was once a perfectly valid assumption, when data was scarce; today, there is an abundance of data, this only leads to factual overload and a blackout of information), or else they imagine that information experts know what data executives and professionals need to obtain information.

Data specialists are "toolers", that is, they know what is the "tool" (information and communication technologies) that should be used, but who needs to decide are the managers, so managers should think well what information for them is, that is, what is the information relevant to decision-making, at every moment. Until this change happens the popular Departments of Systems and Information Technologies will continue to be cost centers and not result centers, as they should be.

So, I suggest that top public and private managers abandon their old habits and acquire new habits, since if they do not, organizations will be called into question, as well as jobs, social position and opportunities for many people - especially middle-aged and middle-aged managers, who tend to have less mobility and feel more uncomfortable in their work, in their position, in their relationships and in their behavior.

\subsection{The Social Impact of Information}

Around 1680 the French physicist Denis Papin invented the steam engine, thus creating a technology and, with it, a new view of the world - the mechanical universe. Much has been said and written (almost too much) about the impact of new information and communication technologies on material civilization, on goods, services and business. Social impacts are important and some of these impacts are recognized by everyone: any such change causes an explosion of entrepreneurial initiative.

We are now living in a phase caused by information and biology. As the previous phases the wave of entrepreneurship is not only restricted to small ones, but also to large enterprises, that is, to technology: social innovations are equally entrepreneurial and important. Some of the social innovations of the industrial revolution are for example the public service, the post office, the commercial banking, etc. Similarly, the contemporary entrepreneurial initiative related to information and communication technologies will be important mainly in politics, government, education and the economy.

Another important social impact of information is visible and discussed: it is the impact on the national state and particularly on the hypertrophy of the typical national state of the twentieth century. Information today is transnational, as is money, information has no "homeland".

If information has no borders, it also allows the development of new "transnational" communities of people who may not be in contact with each other because they are communicating with each other, thanks to information and communication technologies. The world economy and the "symbolic economy" of capital and credit are an example of these communities.

Another social impact that is rarely discussed is the transformation of the city of the 21 st century, that is, the city arose because of the great technological advance of the 19th century: the ability to transport people by means of transport. It is now being transformed by another breakthrough which is the ability to transport work to people by moving ideas and information. The world's big cities are losing their reason as people can no longer transport people in or out of them (just see how many hours they spend on transport).

Some organizations have already started transporting information to where people are, that is, outside cities: in the manipulation of credit cards, in engineering projects, in payments, etc. We are increasingly moving towards people working from home or from large population centres. The centers 
of large cities are deserted and the skyscrapers built in the last century herald the end of the city centers. The decay will be slow, but what is a fact is that we no longer need these great achievements of the last century, the centralized city, at least not in its current form.

The city may cease to be a center for work and become an information center - the place where information is radiated (news, data, music, etc.). Is the university of the future a "knowledge center" that will transmit information and not a place where students are effectively present? We are sure that there will be major changes, but when they will occur we cannot predict it.

The issue of the right size for a particular task or organization will become one of the most controversial issues. In a mechanical system, higher performance is obtained by increasing the dimensions; higher power means higher production, but this is not valid for biological systems, where size depends on function. Biologists claim that "the mouse knows everything it needs to know in order to be a rat"; in what makes it the mouse, the mouse is far ahead of any other animal, including the human being.

In a society based on information and knowledge size becomes a "function" and therefore a dependent and no longer independent variable. In reality the characteristics of the information imply that the smallest effective size will be the best. The "big" will only be better if the task cannot be carried out otherwise.

For communication to take place, it is necessary that there is information and meaning. Meaning requires communion, that is, if one speaks a different language that we do not know we do not understand.

\subsection{How Managers Use Information}

The rules of the economy have not changed and society is now inserted in an information-based economy, how are companies using information to compete in the market? The concern with the use of information in business is a subject that has been on the agenda of the academy for some time. It is believed that information-based organization is the model of organization of the future, based on knowledge and formed by specialists (Lancaster, 1984).

(Porter \& Millar, 2001), state that the transformations in organizations come from the "information revolution". According to them, there are cost reductions, processing and transmission of information, and these facts bring new forms to the business. They warn managers: "It is necessary to use the information properly for organizations to achieve competitive advantages."

Currently the information is used in several ways. Information is used to know how customers act, to control stocks, increase productivity, etc. Information can be an asset, or simply a decision support tool. In several publications, information is treated for common purposes, but not always explicit.

\subsubsection{Cost Reduction}

The search for cost reduction is the initial proposition of the use of Information Technology (IT) (Martin, 1987). Through the restructuring of organizational functions and introduction of efficient transactional systems, it has been sought to reduce paper traffic in offices and automation of various basic activities. In the model of analysis of the computerization of the company, it is perceived that the cost reduction is characteristic of the first stage of evolution of information technology in organizations.

It is perceived that information can change costs in any part of an organization's value chain (Roberts, 1985). In the past, emphasis was placed on cost reduction through repetitive processing of information, as well as in the manufacturing line can reduce cost, since production processes information necessary to control stocks of raw materials, time / machine available etc.

For Howell (2001), cost reduction initiatives have been practiced in seven ways:

- Cost analysis and profitability - aiming to understand the cost direction and identify the most profitable products, using, for example, ABC costing. 
- Elimination of waste and focus on operations - knowing what the costs and the different customers, eliminate products and customers of low profitability, to reduce costs in general.

- Focused and horizontal organizations - oriented more to customer needs and expectations than internal forecasts and expectations, resulting in alignment and speed of processes to generate customer satisfaction.

- $\quad$ Target costing - based on the price at which customers are willing to pay for the product/service.

- Supply chain management, value chain analysis and outsourcing - means understanding how costs originate and the likely ways of decreasing.

- Kaizen costing - or costing improvement means continuously being aware of opportunities that bring business cost cuts, which can be within an organizational culture of its own.

- Asset savings - invest only in the assets necessary for business development, seeking to minimize waste.

Regarding a firm's supply chain, Fine (1982) suggests that it should be a set of supply chains. In the management of the chain, upstream (on the side of suppliers) and downstream (on the side of customers), the firm must seek to acquire speed for its chain, to achieve cost reductions. One of the benefits of supply chain management is the reduction of stocks. In addition, the capacity generated by this chain allows the specialization of activities, for each organization that is part of the chain, to bring reduction in operations, either in time or in cost. All this based on IT infrastructure and a rich flow of information.

The fluid that moves this chain is information. In the optimal adjustment of information traffic between the company and suppliers, there will be an adequate supply of supplies in time and cost. With the basic information on the customer side, the company will be able to compete, having the notion of the needs and preferences of consumers of its products, enabling delivery on time and with the required (or expected) characteristics.

In the formation of target costing (Shapiro \& Varian, 1999), they recall that, in the information economy, informational goods have a high cost of production, but are cheap for reproduction. In other words, it is to state that "a good information involves high fixed costs, but low marginal costs." This implies "the cost of information according to its value, not its cost." The reduction of cost for the strategic use of information entails gains for the competitiveness of the organization and contributes indirectly to the aggregation of value for the product and/or to the firm's own value chain.

\subsubsection{Value Creation}

For researchers in industrial economics, value is how much consumers are willing to pay more for a product or service (Porter, 1984). A business becomes profitable as the value created exceeds its costs. And the intensive use of IT allows the expansion of this gain. Second (Porter \& Millar, 1984), each value activity, within the value chain, uses physical and informational components. IT is responsible for capturing, manipulating, and distributing the necessary information for each activity. The creation of value by IT is directed to the efficiency that it promotes to the processes arranged in the value chain. In the case of outbound logistics activity, how much faster can the delivery of the product to the customer be with the use of IT? It is up to management to ask this question in a way that understands how IT would bring benefits, or, in other words, create value.

For Ramirez (1999), the ideas of value originating in the industry are limited. There is an alternative that goes beyond the value chain - the co-production of value. While for the industrial economy the value is created sequentially, within a value chain, perceiving the aggregation (or addition) and the destruction of value by the consumer, in the co-production of value this considers the creation of value in a non-linear, interactive way, with several authors in the production process, and in a transitive way. Moreover, consumers, in this perspective, do not destroy value.

What Ramirez (1999) developed is a framework that gives a new vision about value creation. Above all, we highlight the interaction between economic actors, interconnectivity, and the 
synchronization of actions. This idea corroborated by Stabell and Fjeldstad (1984), when they state that the logic of creating value in a network is through linking between customers.

Sawhney (1984) attributes to synchronization a way to achieve better results for the business. This means using information in a synchronized way in the business. Organizations should separate product-focused resources into a customer-focused resource strategy, but without having to tear down the walls of companies, or even hastily join business units. The answer is to unify the information about customers, dispersed in the company, and use it to maximize its usefulness and application.

Litan and Rivlin (1984), in a study on the impact of the Internet on the economy, conclude that this technology provides much more targeted benefits to improve consumer convenience and choice than to increase productivity and lower prices. That is, the Internet has been present in people's lives, as a mechanism that, in the end, transmits information. It is a real weapon in the hands of consumers, making them better informed about what they want, what options are available for choice, reducing bureaucracy, among others.

For Horovitz (2001), it is necessary to go beyond satisfaction. You must create a link between the customer and the company. To have this bond, it is up to the company: a) to conquer the customer, b) to make the customer satisfied and then; c) develop loyalty. To achieve, it takes two types of information: a) information for targeting - identifying which customers are b) information for customization - to adapt the product / service according to the needs of customers.

For satisfaction, the ideal is to exceed the initial expectations of the customer. It is necessary to capture four types of information: a) information necessary to adapt the delivery service to the specifications of each customer; feedback information from dissatisfied customers; c) specific information on how to delight each customer; d) information that matches the delivery service (example: quality indicators).

Loyalty is the third level. It is loyalty that guarantees a new purchase, which requires a constant reinforcement of the satisfaction generated previously. In a plan to ensure customer loyalty, an IS is required to provide details of each customer, including a) buying behavior (what, when, how much, where, and why); b) communication preferences (mail, e-mail, fax, telephone, visits); c) constant updating on the consumer; d) cost/benefit (overall and for each customer).

\subsubsection{Interconnectivity, Networks, and Value Creation}

The creation of value from interconnectivity is causally linked to the ability to form networks. Networks have been used to transport people, goods, and information between two distinct points, or more. These types of networks constitute network-based businesses, which can be exemplified, such as telecommunications operators, transportation companies, financial institutions and even health organizations.

For Sawhney and Parikh (1995), the network is the economy. A network a means of conducting information, no matter its complexity. The intelligence of a network is in its functionality, which is the way to distribute, store, create or modify information. The Internet is a smart digital network, capable of expanding the usefulness of information in several ways. And that means creating value.

To create value in a network, no matter what, you need to understand two components of intelligence: the backend and the front end. Modern networks push back-end and front-end intelligences in opposite directions. Back-end intelligence is said to be the infrastructure shared by the main purpose of the network, while front-end intelligence is fragmented in several ways on the periphery of the network, where users are. In this way, an organization can mobilize parts of intelligence that are in the network, such as molecules. The use of skills mobilization brings profound organizational changes. Connected across networks, different organizations can easily combine their capabilities and resources into a temporary and flexible alliance to explore market opportunities.

(Fine, 1999), states that it is essential, to achieve success, to understand the complexity and dynamics of the forces working in the sector and to develop maps of the company's supply chain. This means having a map that allows you to look at the three dimensions of the supply chain: companies, 
technologies, and the network of capabilities. A map is the beginning of the process of reformulation of a company's chain of capabilities, in which the following is identified: (a) the organizations involved in the company's activities; (b) the subsystems provided by these undertakings; (c) the capabilities they bring to the value proposition; (d) the technological contributions of each to the company's final product.

\subsubsection{Innovation}

The information economy requires organizations that are engaged in the constant pursuit of innovation. Innovative and dynamic profiles are requirements for planning Internet operations. In turn, technological systems need to be flexible, so that they support modifications of products, processes, and the organization itself. The use of information provides new types of products and services, which leads to mass customization and new types of business. New business can be characterized by the transformation of an existing business through the intensive use of information, or in the creation of another business.

In the Information Economy companies are trying to innovate with the best interaction between their product development departments. Through software, the areas of product design and engineering "talk" more productively. It seeks to improve information traffic allowing the optimization of information flows and the reduction of the development time of a project. Traditional innovation based on trial and error promotes a lot of waste. With the use of information, this waste is minimized.

The interaction looking for innovation also happens in the relationship between the company and customers. Companies provide their customers with tools that, using the Internet, provide the selection and manipulation of product design and development information. In other words, companies are allowing customers to create products. This action improves customer satisfaction, which is often not met simply because marketing research has not been able to identify your needs. Companies provide the tool, and customers become co-responsible in product innovation. Finally, there are products closer to the needs of customers and in less time.

Information also provides innovation through learning. The exploration of learning in the organization is not a luxury, but a necessity. This need makes the act of learning set up as a way for companies to discover their future. The flow of information becomes, then, essential to the learning process. Combined with learning, competitive intelligence is aimed at anticipating changes in the competitive environment. Business opportunities are based on validation and refining the action of ideas and projects from the constant monitoring of the environment in which the organization is inserted. However, there is only intelligence when facts, data, and trends are enriched and interpreted. For this, ICT's offer tools for search, monitoring, observation and forecasting. More specifically, they refer to content management, enabling access and sharing of knowledge, regardless of time and space.

"Thus, it is necessary to consider that a company does not innovate alone, because the sources of information, knowledge and innovation can be located both inside and outside it. The process of innovation is an interactive process, carried out with the contribution of various economic and social agents who have different types of information and knowledge" (Lemos, 1984).

\subsubsection{Risk Reduction}

Risk is an inherent part of the business, and each manager must determine the risk to which they will be prone, given rates of return and growth. When the organization is executing, the organization becomes the target of potential risks. In this case, leaving a stable position and moving to make changes, an organization can have four risk generating: a) changes in IT - new hardware, new software, and systems reconfiguration; b) organizational changes - new management structure, new guidelines, merger; c) change in processes - new products, new market, acquisitions; personnel changes - loss of important executives, new team, new president. It is then up to the management to have an effective control of these sources, and the information becomes an element of control. 


\subsubsection{Virtualization}

For Evans and Wurster (1984), the Information Economy structures the physical value chain. In turn, information can recreate the value chain according to the established business by taking a new form - the virtual one. Virtualization is a condition that transcends the physical aspect of the organization. The Internet has provided a new economic environment for organizations. This means new channels of communication and exchange between economic agents. In this environment, information becomes a vital material for survival. To characterize this situation, the ICDT (Information, Communication, Distribution and Transaction) outlines the four strategies that companies have used to compete on the Internet: a) Virtual Information Space; b) Virtual Communication Space; c) Virtual Distribution Space; d) Virtual Transaction Space.

The possibility of virtualizing products and services, that is, transforming matter into bits, is a capacity acquired by some organizations in recent years, which, through ICT's, seek to differentiate themselves in the market and transfer to the consumer the power of choice. In other words, this means end outing products/services as being of the anywhere type (capable of being used /accessed from anywhere), anytime (able to be used/accessed at any time) and no matter (not made of matter, but bits),(Davis, S.; Meyer, C., 1999).

Thus, it is indicated that information is an important element in the realization of Business in the Digital Age (NED). And these businesses belong to an emerging trend that has a great potential for innovation in the economy. For (Rayport \& Sviokla, 1995), the traditional value chain model treats information as a supporting element. In fact, the information will make a difference when management visualizes the new environment in which it operates - marketspace. In this digital environment, the differences are perceived by a) content; b) context; (c) infrastructure.

In the digital environment, companies need to look at another type of value chain - the virtual value chain. Companies start competing in two worlds: physical and virtual. In physical form, the information serves to control the chain, whether in stocks, logistics or process. In the virtual, the information is used to provide a new type of value to the client. Value creation in the virtual value chain involves five sequential steps: collection, organization, selection, synthesis, and distribution of information. It was observed that companies adopt the creation of virtual value in three stages: a) visibility - when managers use information for coordination and control of activities of the physical value chain; b) similarity capacity - replacement of steps from the physical chain to the virtual chain; c) new customer relationships - new ways to provide value to the customer.

To be embedded in the information economy, it is necessary that the organization is based on an appropriate business model. Second (Venkatraman \& Henderson, 1998), in times of high turbulence and rapid transformations, the strategy of having a virtual organization is the most appropriate. For virtualization of an organization, it is necessary to note:

- Customer interaction - new opportunity in the company-customer relationship (B2C - Business to Consumer), in which the customer can remotely try products and services.

- Asset configuration - so that the organization can stop only about its core competency, maximizing and making its relationship with suppliers and subcontractors more flexible.

- Knowledge - as the basic asset of the organization (to the detriment of land, machinery, and capital), so that they can be organized from specialist units, in stage 1 , to the formation of a community of specialists.

Virtualizing means having a new way of operating. It also means having a new supply chain design - a virtual supply chain. A virtual integration means gain in speed, agility and focus on skills. The following are the characteristics that determine virtualization:

- $\quad$ speed - where business esits are processed in minutes or hours, rather than weeks or months. 
- $\quad$ strategy - focused on skills and the creation of links with suppliers, subcontractors, and partners, aiming to strengthen the business model with the competencies of external organizations.

- c) customization - through the relationship with customers through the Web and with the established value chain.

- d) ICT's architecture - where several applications interrelate seeking to connect customers, suppliers, partners, and internal functions, to optimize the capacity of systems, work on robust storage capacity and integrate physical and digital infrastructures.

- e) teams - provided with tools and communications systems, guaranteed by a distinct culture, which promotes fast responses, business quality and customer focus.

\subsubsection{Product Differentiation}

The differentiation of product or service through information is a strategy that aims to gain competitive advantages. New products have been offered with different informational content. For TVs, the command menus are available on the screen and the viewer chooses which language they prefer to read in. The DVD presents, in addition to the options of different languages for the audio and subtitle of a movie, the possibility to navigate through the media using the counter (hours, minutes and seconds). It is the consumer enjoying the freedom of choice and broadening their satisfaction.

The operating systems of personal computers are differentiated by the information they carry. It's the dispute between Windows and MacOS on the question of who's better. Or in the case of mobile phones, in which each can perform its own functions, from the simplest search in the internal schedule of phones to the transfer of data via the Internet.

They are the banks that best use information in the transformation of their own business. In the past this segment had a set of limited offers. Currently the range of service is quite wide. In the search for attraction and customer satisfaction, banks gather in the virtual world much of their services, identifying and classifying individual needs. On the Web, the informational lows the customer to differentiate and customize the products and services.

\subsection{Information for Wealth Creation}

Companies are created to generate wealth and not to control costs. But this is not reflected in traditional measurements. Companies are also created to generate wealth and not to be liquidated. This requires information that allows managers to make informed judgments. For wealth creation managers need information on four types of information:

- Basic information - is the information of an operational nature that allows to make concrete decisions, such as cash flow and liquidity projections, invoices to be received and payable, etc. It can be compared to the information that the doctor needs in a routine medical consultation of a client - weight, temperature, blood pressure and urine analysis, etc.

- Productivity information - is information on the productivity of key resources, that is, the productivity of the total factor. This explains the growing popularity of value added analysis (VAL) that is based on something we have known for a long time: what we normally call profit, the money left to pay capital, is usually not at all profit. Until a business profits higher than its cost of capital, it works at a loss.

The company continues to give less to the economy than what it consumes in resources. It does not cover all of its costs unless the advertised profit exceeds the cost of capital. Until then, it does not create wealth: it destroys it.

Another important information to measure productivity is benchmarking - comparing our performance with the best performance in the industry or better with the absolute best performance. 
Benchmarking correctly assumes that what an organization does any other organization can also do. It also presumes to be at least as good as the leader is a prerequisite for being competitive.

- Information about competence - leadership is based on being able to do something that others cannot do or have difficulty doing, even harm. It is based on nuclear competences 1 that combine market value or value for the customer with a special capacity of the producer or supplier.

Core skills are different in all organizations: they are, so to speak, part of a company's personality; All organisations need a core competency: innovation and all organizations need a way to register and evaluate their innovative performance.

- Information on the allocation of resources - for the creation of wealth, it is important to allocate scarce resources: capital and efficient people. These make into action the information that managers need for business management, that is, whether the company will perform well or poorly.

These four types of information only inform managers about the current business. They inform and guide tactics. As for the strategy, managers need information about the global and immediate environment, and internal information about the competence and capacity of the organization's resources, that is, information about what is outside and what is inside. Managers must be sure that within organizations there are only cost centers. The only profit center is a customer whose check has not been returned, that is, it is outside the organization. Big changes start outside organizations. For example, a retailer might know a lot about the people who buy in your store (your customers). But no matter how successful you are, no retailer has more than a small market share as customers. It is always by non-customers that basic changes begin and become meaningful.

The commercial role in the financial sector did not originate in the banks. Molecular biology and genetic engineering were not developed by the pharmaceutical industry. While most businesses continue to operate only locally or regionally, they all face, at least potentially, global competition.

Of course, not all information about the environment is available. There is no information, even of little confidence, about the economic, political, technological, etc. situation of some countries. Even in countries where this information is available, some managers are distracted by it. A serious cause of business failure is the vulgar assumption of A serious cause of business failure is the vulgar assumption that conditions - market and environment trends in general, should be as managers think they are or at least as they think they should be.

An appropriate information system must include information that makes managers question this assumption. It should get them to ask the right questions, not just to give them the information they expect. This presupposes that managers first know what information they need to rely on strategic decision-making. It also requires that they obtain this information with some regularity and that it be filtered. Finally, it requires them to systematically integrate information into their strategic decision-making.

Many managers have not yet begun to worry about strategic information. Thinking about the information that managers need requires someone who knows and understands the science of highly specialized information. There is too much information so that no experts can solve the problem. The sources of information are of total diversity and it takes someone who can filter the essential information of the complementary and the non-interest. Companies themselves generate information, such as about their customers, suppliers, their products, etc. But information about the global and immediate environment can only be obtained from external sources.

Another need for help is information specialists who must organize/architect the information, in such a way as to question and question the company's current strategy. Providing data is not enough. 
Our traditional mindset, even though managers can use mathematical and statistical techniques and impenetrable sociological slang, have always understood in some way that the business was cheap buying and selling expensive. The new approach defines a business as an organization that adds value and creates wealth.

\subsection{The New Information-Based Organization}

The tendency of large companies/organizations is to have fewer and fewer levels of management than the current ones and probably no more than a third of managers. In its structure and in its problems and management concerns will have few similarities with the typical industrial companies of the 1950s, which our manuals still consider as the norm. Instead, it is very likely to be like organizations that neither managers nor management academics pay much attention to today. The typical organization will be based on information, including signals (weak and strong), and knowledge to analyze and interpret this information and these signals. That is why it's going to be what I call an informationbased organization.

Organizations mainly large ones will have few alternatives other than to become information based. On the one hand, demographics demand this change. The center of gravity of employment is rapidly moving away from manual and administrative workers and getting closer to knowledge workers who resist the model of control and command that current organizations have been seeking in the military sector for 100 years. On the other hand, the economy, socio-cultural and environmental changes, as well as information and communication technologies also determine change, especially the need for companies to innovate and be entrepreneurs. So far most computer users continue to use new information and communication technologies just to do what they have always done faster, 'chewing' conventional numbers. But as soon as a company/organization takes the first steps towards data for information, its decision-making processes, its management structure and the way it does its work begin to change. This requires managers (top, coordination or intermediate and operational) to know what information to rely on in decision-making.

Information-based organizations, due to their flatter structure, will be more like companies a century ago than today's large companies. At that time knowledge resided in the top managers and the other employees did as they were told to do. In information-based organizations, knowledge will be primarily at the bottom of the minds of experts who do different work and orient themselves.

- But what can one say today of the future information-based organization?

- What will be your main problems?

Let us look at the needs first. In an orchestra several musicians and their conductor can play together because they all have the same score. She tells the piper and the helmsman what to play and when and tells the conductor what she expects from each of them and when. Musicians are experts, you can't tell them how to do their job. But the conductor guides the horn player's skill and knowledge to the musicians' joint performance. This guidance is what the leaders of an informationbased company must achieve.

Information-based organizations require clear, simple, and common objectives that translate into actions and need to focus on global and specific objectives, but few, that is, managers need to focus on few variables (information), track their progress, and make the decision to correct any deviations. An information-based organization should be structured around goals that clearly show the performance expectations of the organization and for each party (business unit or area of responsibility) and for each expert and around an organized feedback that compares the results with the performance expectations, so that each element can exercise self-control.

The other need for information-based organization is to share the same information about a particular fact or event, so that everyone can be held responsible for the information. Responsibility for information to third parties is increasingly understood, especially in medium-sized enterprises. 
But the responsibility for information to itself remains neglected. In an organization manager must constantly think about what information they need to perform their task and make their contribution to the results (overall and business unit and or area of responsibility).

Perhaps it is the most radical break with the way the most computerised organisations continue to be managed. Managers assume that the more data (stored in information and communication technologies), the more information - which was a perfectly valid assumption yesterday, when data was scarce, but leads to an excess of data and the lack of information, today that they are many - or believe that information specialists know the data that managers need to have quality information. Managers need to think about what information they need to make the best decisions: first to know what they are doing; then to be able to decide what they should do; and finally to assess whether they're doing well. Until this happens, it is likely that it departments will continue to be cost centers rather than become the result centers they should be.

\subsection{The Digital Society}

It will not be an exaggeration or a blatant misunderstanding, to affirm that the current society is increasingly qualified by the digital adjective, where new information and communication technologies (ICT's) have constant daily influence, configuring themselves as mediators of social relations, the economy and even the way to produce / disseminate knowledge. There are forms of knowledge absorption about users in a ubiquitous way, in which ICTs be new forms of surveillance (Lupton, 2015, p. 02; p. 189). Digital ICTs play a crucial role in the process of globalization, as a phenomenon characterized by the wide circulation of people, ideas, and habits, which although it has not started historically with technologies, develops at high speed through them (De Mul, 2015, p. 106).

The increasing insertion of Information and Communication Technologies (ICT's) in people's daily lives has promoted a deep dependency relationship between them. In this context, daily actions have become essentially informational, given the need for mediation for their performance.

The society digital is a complex society of technological innovation and communication, in which there is the creation of new environments and changes in the organizational dynamics of people, in the way people understand reality, changing the wayt hey relate to the environment, with other people and how, they conceive in the face of reality itself. Both senses can be understood, as arising from the informational revolution, promoted mainly from the attempts to understand human intelligence, via computational bases.

The works developed by Turing (1950) had great influence in the studies of the second half of the twentieth century, including philosophy, mainly because of its algorithmic approach to the nature of thought, in which he proposes the thesis, according to which, "thinking is calculating" (Turing, 1950, p. 436). This is that, given that digital computers operate from calculations and manipulate rules for the organization of symbols, if we consider that thinking consists, in the activity of manipulating symbols, according to a set of logical rules, constituting algorithms, then digital computers could, in principle, think. Once intelligent thinking is understood mechanically, it would be possible to construct mechanical models of the structure and dynamics of this type of thought. This understanding allowed the development of mechanical models of the mind, which initially generated two aspects in The Teixeira Cognitive Science, (1998):

- Strong Artificial Intelligence - is one in which mechanical models of the mind, when successful, not only simulate/ emulate mental activities, but explain and instantiate such activities.

- Weak Artificial Intelligence - is one in which the model is only an explanatory, limited tool of intelligent mental activity.

The common point of such nodes is that both accept the thesis that to simulate is to explain, in order to attribute to mechanical models, the value of theories, in which the computer is used, as a fundamental tool. As for the social sphere, the development of studies of information theory promoted 
the social changes that we are currently experiencing and that have generated new types of problems, especially those that relate to action / technology / environment. Given its impact on the academic and social spheres, the approximation between Philosophy and Information Science, and the role of computers in the development of theories, theoretical production occurred concomitantly with technological improvement.

Floridi (2008, p. 3-4), states that during the second half of the 20th century events such as: the massification of the computer, which promoted the generation of the "personal computer"; the advancement of scientific discoveries in function of the use of ICT; and the emergence of new ways of experiment the world, from such technologies. These events illustrate the influence of ICT's in various areas of society (sociological, economic, scientific, and cultural), providing elements for the characterization of it, such as the information and knowledge society. According to Floridi (2002, p. 127): "Post-industrial societies are nourished by information".

ICT's acquire a central role in the characterization of the digital society, to the extent that they are present and related to the person and their well-being, and in their continuous use in everyday situations (e.g., leisure, work, etc.). Constitutes a dependency relationship, between the person and the TIC's. This relationship is strengthened, according to Floridi, from the following factors:

- Increasing the potency of ICT's, while reducing their cost of production and marketing.

- Improvement of ICT's in their interaction potential (machine-machine and man-machine);

- The rise of the zettabyte's era (dated 2010).

The factors indicated are responsible for the approximation between people and ICT's, generating a deep relationship of dependence for the performance of routine actions in today's world. This dependence is based on the digital presence, as a mediator of common actions, such as financial movement (home banking), the acquisition of products and services (virtual stores, e-commerce), personal and professional interrelationship (via social networks, such as Facebook, Twitter, or dating apps such as Tinder), access to movies (via streaming, YouTube, Netflix, etc.), urban mobility (via app, Uber, Taxi 99), making connections (using the network, via Skype, Whatsapp), the practice of physical activity (Runkeeper, for example), professional activities via SOHO (small office / home office), political organization (via websites or social networks), among others. Situations in which there is no mediation of internet-connected artefacts by the persons, but which require technological mediation by the service to be requested, such as: payment by credit card for face-to-face purchases, biometric systems for the removal of books in libraries, among others.

In addition to understanding the influence of ICT's on the constitution and alteration of people's self, the three types of self highlighted by Floridi $(2014$, p. 60) are explained:

- Personal Identity - it concerns "who we are". We live in an era where people spend a great deal of time transmitting information about themselves, interacting digitally with other people, and that is a good example of how ICT is affecting and shaping people's personal identity.

- Self-conception - consists of "who we think we are".

- Social self - it concerns what we are from the thought of other people.

It is mainly this third notion of self that ICT's have a deeper channel of action in the conception of people's identity, because there is a growing support and overvaluation of social networks, illustrated, for example, by the intensification of a "narcissistic culture".

The Web enhances narcissistic culture, typical of our time, by expanding the forms of selfcelebration and self-promotion. Relationship sites, in turn, end up encouraging vanity and competition. Young people strive to show in their profiles, photos and texts that value them and promote the increase in the number of people they add as "friends". This type of behavior is justified by a constant 
search for attention and recognition. The ease of access to information about themselves generated by third parties, promotes self-understanding from others (social self), constitutes a scenario in which people, especially those who correspond to Generation Z, feed the network, with personal information intensely.

The greatest of all changes is the transformation of the information and knowledge society into the digital society. The centre of work was 'distance work - telework'. In developed country societies, access to good jobs and a professional career will increasingly depend on a university degree with distance work, anywhere, in a country, in the globalized world. That is, the logical result, since we stopped working in the office and in large urban centers, it was through intellectual work and teleworking was reached at home or elsewhere, outside the large urban centers. This last step represents a break with the past.

- The fact that knowledge and education have been a passport to the achievement of good jobs and a career has meant above all that in society, companies are no longer the only way for someone to progress in life and have become one of several opportunities available.

- Knowledge has become the capital of developed economies and knowledge workers, which determines the values and norms of society.

The great challenge for developed countries is to maintain the commitment, with the economic performance necessary for organizations and countries to continue to be competitive. Governance and entrepreneurship contain the entrepreneurial spirit. They are not antagonistic concepts, nor mutually exclusive. Both are always necessary and at the same time. Both have to be coordinated, i.e. both have to work together. No existing organization can survive without innovation and the same time without being managed.

\section{DISCUSSION AND CLUES TO FURTHER INVESTIGATIONS}

Rarely is information totally useless. But often a lot of information is no longer analysed or transmitted because, in the general context, its priority is small. Soon, it becomes useless. No information is free, and all information can bring benefits. This relationship between expenses and benefits should be carefully analyzed.

Generic studies related to spending and benefits are agglutinated under the name of information economics. Information economics has often used theories and methods of economic analysis, in particular cost-benefit analyses, as an evaluation tool. Although the results are often not yet satisfactory, the first step has already been taken with the growing awareness of experts in the need to visualize information as an economic good and, from there, treat it as such.

This article sought to develop, based on existing theories, the framework that structures the use of information by organizations. In a generic way, it is understood that such use, aims to achieve the best competitive positioning in the market, is directed to six generic strategies: cost reduction, value creation, innovation, risk reduction, virtualization, and product differentiation (Figure 2).

Source: own elaboration

At this moment there is the beginning of the process of construction of theory, which consisted of abstraction, generalization, relationship, selection, synthesis, and idealization. From now on, serving as an indicator for future work, the construction of the measurement instrument for each of the proposed dimensions, with the objective of validating the constructs cited and the theoretical confirmation $\mathrm{p}$ itself The quantification of the use of information, in the structure proposed here, will allow the establishment of a degree within an appropriate scale. With this, it will be possible to discriminate punctually the positions of organizations in the model. It is remembered that the 


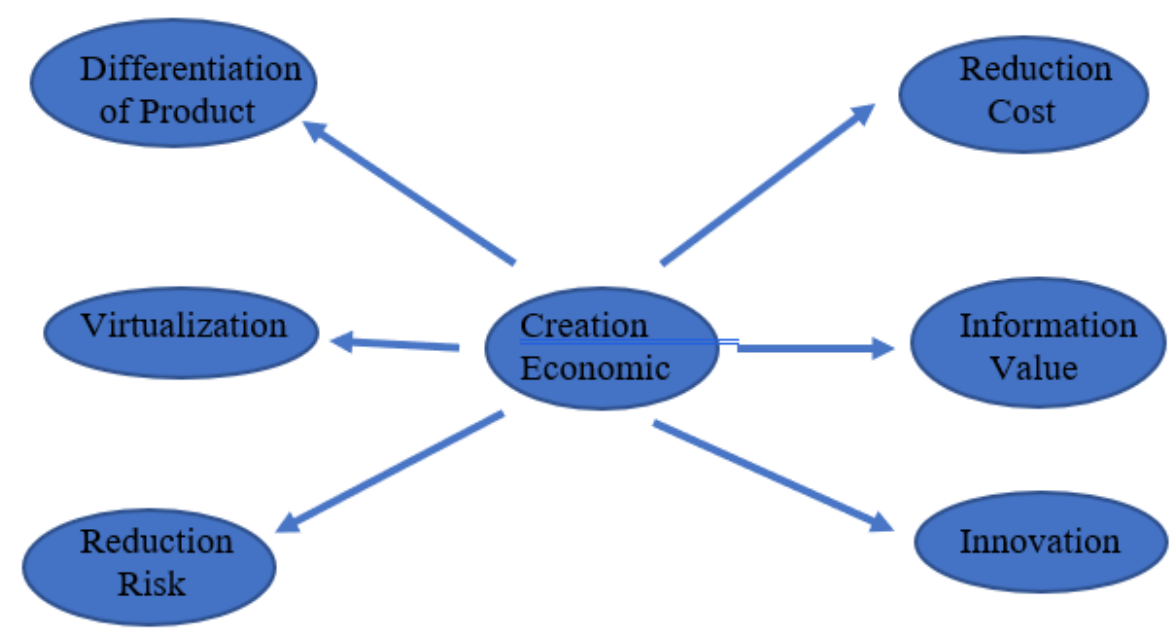

measure, once created, is not the end, but a means within the process of description, differentiation, explanation, prediction, diagnosis, or decision making.

\subsection{Key Terms and Definitions}

Date: The data does not carry any sense or meaning of the facts, images or sounds, since they lack relational elements essential to the establishment of a complete meaning, requiring a relational structure internal to a cognitive purpose.

Information: The information as "data with value for decision making". The description of this concept refers to the effect that information, such as reduction of uncertainty, we consider, as an example of how to process information.

Knowledge: The information can be considered as a "substance" which can be acquired, stored, and possessed by a person or group and transmitted from person to person or from group to group. The information has certain stability and perhaps is better faced as existing at the society level.

Ethics: According to (Du Mont, 1991), ethics aims to establish principles of human behavior that help people choose alternative forms of action. These considerations lead to the definitions of ethics and morals, instigating us to refer to deontology as the study of codes or ethics of professions. (Targino, 2006, p. 135) states that definitions of ethics originate from the "Greek term ethos, as etymology suggests, is the part of philosophy that deals with reflection on customs, encompassing the guidelines". While the moral "term of Latin mores concerns the acts and customs per se, that is, the set of objective norms of conduct, changeable in time and space".

Information Economy: The term "information economics" began to appear in the economic literature from 1960. In the Information Sciences it emerged initially related to evaluation studies. In the 1980s, the cost and effectiveness approach of information services was included, followed by discussions about the value of information for the user and the productivity of information at work. The literature on the subject has been published more markedly in the United States and Great Britain.

The study of information economics presupposes the definition of information. In a popular sense, it is understood as information all the clarification that can be provided to anyone about what they ask. Knowledge in any form through which it can be transferred. Many information scientists define information in terms of the method of presentation. For example, "information is accumulated 
knowledge". Others define it as a process in which data becomes information, knowledge and even wisdom,

The study of information economics has often used classical economic theories. However, during studies and practical experiments, some special features of the information have emerged:

- Information products have value, but their benefit also depends on the user's ability to exploit them.

- Information is not consumed through use; only time, sometimes, takes unimportant information.

- Information is not a constant, that is, it usually cannot be quantified.

- Information is an abstraction, that is, it is produced, disseminated, accumulated, and used for different purposes and purposes. This characteristic causes a lot of confusion, for example, when one estimates the value of the information depending on what another is willing to pay for it.

- News information is usually produced with public resources (especially basic research), and these costs are usually not imputed for market price-setting purposes.

- The real benefit of information is difficult to measure because it is limited to its use, which is impractical.

The study of information economics becomes problematic in the face of these characteristics of information. The information economy is, however, becoming an important object of research in the Information Sciences.

Communication: The concept of information is always present in journalistic products. The terms informative journalism or informational content are linked to the news. When you talk about news, you automatically talk about information for journalism. What is the content of journalism? The news information, that is, the news is the topic, while the information describes the topic. For example: news - economic crisis in Europe - information is everything that characterizes / describes the economic crisis from its origin to its consequences. The media (print or electronic), despite suffering strong competition from other media, the newspaper / newsletter continues to affirm its vocation to inform us of everything and all dimensions of our presence in the world.

Skills: Information and knowledge have become integral factors of production. Other values come into play: to innovate and deal with irregularities, it takes autonomy and responsibility, as well as a knowledge of processes and products. Information and knowledge have always been part of productive work, but now there is visibility, and its importance is recognized. As knowledge can only be mobilized by workers, by the human person, logic is reversed. Work is no longer the factor that is something external to the worker and is again something intrinsic to those who perform it.

The transformations that occurred in the world of work have put the human being back at the center of production. We then start talking about skills, not more of qualification for a job or a certain job. It is the person, with its most complete characteristics that matters. For a peasant or a craftsman, working meant employing and developing their knowledge, relying on rules transmitted by more experienced peers (masters) and acquired by the individual through a series of tests (...) it was the direct and immediate expression of practical intelligence.

It was the invention of work as a separate object from the worker that served to qualify another type of social relationship, that of objective work and the necessary capacities to accomplish it. Hence the separation between the objectivity of work and the subjectivity of the worker. To get out of this logic of objectification, it was necessary that the work was subjected again. This meant the inclination towards the logic of competence, which was called the "model of competence".

Osty (2000, p. 9) considers that the notion of competence shows the emergence of a new mode of management and recognition of the knowledge required by work situations, revealing the extent of the transformations of work in the last twenty years of the twentieth century. 
Second (Zarifian, 2003, p. 37), competence is a new form of qualification, a new way of qualifying. But it is not about qualification as "a particular and always dominant historical mode: that of qualification for the job", but rather in a new way: "the construction of qualification". This construction of qualification, given the new conditions of production, would replace the two previous models: the model of the profession and the job model (or employment).

The model of the profession began to be built in urban artisanal corporations. The metier or function, a term used since the middle ages by medieval corporations, presupposed a means of learning and a social pertinence. This model began to be attacked at the end of the 18th century because it seemed an obstacle to the transformation and rationalization of working methods. Defines skill as "the ability to perform a task or a set of tasks, in accordance with certain standards required by the organization", involving theoretical knowledge and personal skills. The use of the notion of competence began to appear when organizations had to recognize people's competencies, regardless of the job they held. The emergence of the competency model represented a new moment, whose practical bases are still being developed.

For Brandão (1999, p. 22), the meaning of the word competence has been expanding since the end of the middle ages. There was, first, a legal meaning: "faculty assigned to someone or an institution, to assess and judge certain issues." Later came an extension of the concept: "social recognition of someone's ability to speak out on a specific subject."

Nordhaug (1998, p. 10) classifies skills into: technical, interpersonal, and conceptual. Technical skills are related to methods and processes, designed to conduct a specific activity and skills to use tools and operate equipment related to an activity. Interpersonal skills are human behaviors and interpersonal processes, empathy and social sensitivity, communication skills and the ability to cooperate. Conceptual skills are analytical skills, creativity, problem-solving efficiency, and the ability to recognize potential opportunities or problems. 


\section{REFERENCES}

Alter, S. (1992). Information System - A Management Perspective. Addison-Wesley.

Atmanspacher, H. (1999). Cartesian cut, Heisenberg cut and the concept of complexity. In The quest for a unified theory of information: Proceedings of the second international conference of the foundation science. Gordon and Breach Publishers.

Bateson, G. (1972). Steps to an Ecology of Mind. Balentine Books.

Bausch, K. (2000). The evolution of embodied information: a mosaic. In OLD Saybrook 2 Conference at State University of West Georgia.

Belkin, N. J. (1978). Information concepts for information science. The Journal of Documentation, 34(1), 55-85. doi:10.1108/eb026653

Boisot, M. H. (1998). Knowledge Assets - Securing Competitive Advantage in the Information Age. Oxford University Press.

Boland, R. J. (1987). The In-Formation of Information Systems. In R. J. Boland \& R. A. Hirschheim (Eds.), Critical Issues in Information Systems Research. Wiley.

Boland, R. J., \& Collopy, F. (Eds.). (2004). Managing as Designing. Business Books.

Boland, R. J., Collopy, F., Lyytinen, K., \& Yoo, Y. (2008). Managing as Designing: Lessons from Organization Leaders from the Design Practice of Frank O. Gehry. Design Issues, 24(1), 10-25.

Braman, S. (1989). Defining information: An approach for policymakers. Telecommunications Policy, 13(3), 233-242. doi:10.1016/0308-5961(89)90006-2

Buckland, M. (1991). Information as thing. Journal of the American Society for Information Science, 42(5), 351-360. doi:10.1002/(SICI)1097-4571(199106)42:5<351::AID-ASI5>3.0.CO;2-3

Callaos \& Callaos. (n.d.). Toward a systemic notion of information: Practical consequences. Information science, $5(1)$.

Capurro, R., \& Hjorland, B. (2003). The concept of information. In B. Cronin (Ed.), Annual Review of Information Science and Technology (Vol. 37, pp. 343-411). Academic Press.

Checkland, P., \& Holwell, S. (1998). Information, systems and information systems: making sense of the field. John Wiley \& Sons.

Dahlberg, I. (1978). Concept theory. Information Science, 7(2), 101-107.

Dahlberg, I. (2006). Feature: Interview with Integrant Dahlberg, December 2007. Knowledge Organization, $35(2 / 3)$.

Davenport, T. H. \& Markus, M. L. (1999). Rigor versus Relevance Revisited: Response to Benbasat and Zmud. MIS Quarterly, 23(1), 19-23.

Davenport, T. H., \& Prusak, L. (1997). Information Ecology: Mastering the Information and Knowledge Environment. Oxford University Press.

Davenport, T. H., \& Prusak, L. (1998). Working Knowledge. Harvard Business School Press.

De Mul, J. (2015). Database Identity: Personal and Cultural Identity in the age of Global Datafication. In Crossroads in new media, identity and law: the shape of diversity to come (pp. 97-118). Palgrave Macmillan. doi:10.1057/9781137491268_6

Devlin, K. (1991). Logic and Information. Cambridge University Press.

Devlin, K. (1999). Info Sense: turning information into knowledge. W. H. Freeman and Company.

Douglas, M. (1986). How Institutions Think. Routledge.

Drucker, P. (1969). The Practice of Management. Pan Books. 
Drucker, P. (1989). What Business Can Learn from Nonprofits. Harvard Business Review, 67(4).

Davenport, T., \& Prusak, L. (1998). Working Knowledge. Harvard University Press.

Devlin, K. (1999). Info Sense: turning information into knowledge. W. H. Freeman and Company.

Drucker, P. (1992). Management the Nom-Profit Organization: Principles and Practices. Harper Business.

Drucker, P. (1997). The New Realities - in government and politics, in the economy and in companies, in society and in the world view (4th ed.). Editora Pioneira Novos Umbrais.

Drucker, P. (1999). About the Management Profession (1st ed.). Editora Publicações Dom Quixote, Lda.

Evans, P. B., \& Wurster, T. S. (2000). The explosion of bits: blown to bits. Campus.

Fisher, A. G. B. (1934). The Clash of Progress and Security. Kelley.

Fuchs-Kittowski, K. (1999). Information - neither matter or mind: on the essence and on the evolutionary stage conception of information. In The quest for a unified theory of information: proceedings of the second international conference of the foundation science. Gordon and Breach Publishers.

Gelepithis, P. A. M. (1999). A rudimentary theory of information: Consequences for information science and information systems. In The quest for a unified theory of information: proceedings of the second international conference of the foundation science. Gordon and Breach Publishers.

Haefner, K. (1999). Foreword. In The quest for a unified theory of information: proceedings of the second international conference of the foundation science. Gordon and Breach Publishers.

Handy, C. (1990). The Age of Unreason. Harvard Business Review.

Kirk, J. (1999). Information in Organizations: Directions for Information Management. Information Research, 4(3). http://Informationr.net/ir/4-3/paper57.html

Klein, H. K., \& Hirschleim, R. A. (1987). Social change and the future of information systems development. In R. J. Boland \& R. A. Hirschleim (Eds.), Critical issues in information systems research. John Wiley \& Sons.

Klein, H. K., \& Hirschleim, R. A. (1987). Social change and the future of information systems development. In R. J. Boland \& R. A. Hirschleim (Eds.), Critical issues in information systems research. John Wiley \& Sons.

Lauer, T. W. (2001). Questions and Information: Contrasting metaphors. Information Systems Frontiers, 3(1), 41-48. doi:10.1023/A:1011497503953

Le Moigne, J. L. (1979). Informer la décision ou décider de l'information. E.S. Sciences of Gestion, (1), 863-888.

Mackay, D. M. (1969). Information, Mechanism and Meaning. MIT Press. doi:10.7551/mitpress/3769.001.0001

Miller, J. F. (2002). I = 0 Information has no intrinsic meaning. Information Research, 8(1). http://Informationr. net/ir/8-1/paper140.html

Mokros, H. B. (1993). The impact of a native theory of information on two privileged accounts of personhood. In J. R. Schement \& B. Ruben D. (Eds.), Between communication and information. Transaction Publishers.

Murteira, M., Nicolau, I., Mendes, V. E., \& Martins, A. (2001). Information Services and transition to the knowledge economy in Portugal. IDEG/ISCTE, study conducted for gepe of the Ministry of Economy.

Newman, J. (2001). Some observations on the semantics of information. Information Systems Frontiers, 3(2), 155-167. doi:10.1023/A:1011439305567

Popper, K., \& Eccles, J. C. (1965). La ciencia normal y sus peligros. In La crítica y el desarrollo del conocimiento. Mr. Grijalbo.

Popper, K., \& Eccles, J. C. (1977). The self and its brain: an argument for interactionism. Taylor \& Francis Group. doi:10.1007/978-3-642-61891-8

Porat, M. U. (1997). The Information Economy. Publication Spetial OT. 
Porter \& Millar. (1985, July-August). How Information Gives You Competitive Advantage. Harvard Business Review.

Prusak, J., \& McGee. (1995). Strategic Information Management. Campus Publishing House.

Ruben, B. D. (1992). The communication-information relationship in system-theoretic perspective. Journal of the American Society for Information Science, 43(1), 15-27. doi:10.1002/(SICI)1097-4571(199201)43:1<15::AIDASI2>3.0.CO;2-K

Ruben, B. D. (1993). Integrating concepts for the Information Age: communication, information, mediation and institutions. In J. R. Schement \& B. Ruben D. (Eds.), Between communication and information. Transaction Publishers.

Schement, J. R. (1993). Communication and information. In J. R. Schement \& B. Ruben D. (Eds.), Between communication and information. Transaction Publishers.

Shannon, C. E., \& Weaver, W. (1948). The Mathematical Theory of Communication. The Bell System Technical Journal, 27(3), 379-423, 623-656. doi:10.1002/j.1538-7305.1948.tb01338.x

Shannon, C. E., \& Weaver, W. (1949). The Mathematical Theory of Communication. University of Illionois Press.

Shapiro, C., \& Varian, H. R. (1999). Information Rules - A Strategic Guide to the Network Economy. Harvard Business School Press.

Stamper, R. K. (1973). Information in Business and Administrative Systems. Batsford.

Stamper, R. K. (1985). Towards a theory of information - Information: Mystical fluid or a subject for scientific enquiry? The Computer Journal, 28(3), 195-199. doi:10.1093/comjnl/28.3.195

Sveiby, K. (1998). What is Information? Retrieved from http://InformationR.net/ir/8-1/paper144.html

Tully, J. C. (1985). Information, human activity, and the nature of relevant theory. The Computer Journal, 28(3), 206-210. doi:10.1093/comjnl/28.3.206

Wallerstein, I. (2000). Globalization or the Age of Transiction? A Long Term view of the Trajectory of the World System. Global Economics and Management, 5.

Wersig, G. (1993). Information science: The study of postmodern knowledge usage. Information Processing \& Management, 29(2), 229-239. doi:10.1016/0306-4573(93)90006-Y

Zikmund, W. G. (2000). Business Research Methods (6th ed.). Dryden press.

Zorrinho, C., Serrano, A., \& Lacerda, P. (2003). Manage in Complexity. Syllable Editions. 
Jose Poças Rascão (PhD, ISCTE / ULI) is a Professor of Management Information Systems at the Polytechnic Institute of Setubal, Graduate School of Business Sciences, Portugal. His research is in the Research Unit in the development of enterprise (UNIDE) at the Lisbon University Institute (ISCTE / ULI). Since 2000 he has published 15 books and over 80 research papers in international scholarly academic journals, about on management strategy and management of information. Under his supervision, 17 Masters Theses have been successfully from 2007 to 2018. From 2010 to 2015 was Director of Course Management of Distribution and Logistics. From 2013 to 2014 was Coordinator of Research Center, Polytechnic Institute of Setubal, Graduate School of Business Sciences. From 2000-2004 was Information Systems Management Course Coordinator Polytechnic Institute of Setubal, Graduate School of Business Sciences. He also works the private Management Consultant for large and medium-sized enterprises. He worked the Management Consult at Price Waterhouse and Coopers \& Lybrand between 1989 and 1995. 